\title{
Supporting smoking cessation in chronic obstructive pulmonary disease with behavioral intervention: a randomized controlled trial
}

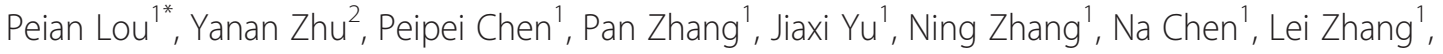
Hongmin $\mathrm{Wu}^{2}$ and Jing Zhao ${ }^{2}$

\begin{abstract}
Background: Cigarette smoking is the major risk factor for chronic obstructive pulmonary disease (COPD). But a fewer smoking cessation measures were conducted in communities for smokers with COPD in China. The aim of our study was to assess the preventive effects of behavioral interventions for smoking cessation and potential impact factors in smokers with COPD in China.
\end{abstract}

Methods: In a randomised controlled smoking cessation trial 3562 patients with COPD who were current smoker were allocated to intervention group received behavioral intervention and control group received the usual care for two years. The primary efficacy endpoint was the complete and continuous abstinence from smoking from the beginning of month 24 to the end of month 30. Participants were followed up at month 48.

Results: Continuous smoking abstinence rates from month 24 to 30 were significantly higher in participants receiving behavioral intervention than in those receiving usual care $(46.4 \%$ vs $3.4 \%, p<0.001)$. Continuous abstinence rates from months 24 to 36 (45.8\% vs 4.0\%) and months 24 to 48 (44.3\% vs 5.1\%) were also higher in participants receiving behavioral intervention than in those control group. Family members or family physicians/ nurses smoking were first identified to influence smoking cessation.

Conclusions: Behavioral intervention doubled the smoking cessation rate in patients with COPD and was complied well by the general practitioners. The family members and family physicians/nurses smoking were the main risk factors for smoking cessation.

Trial registration: Chinese Clinical Trials Registration (ChiCTR-TRC-12001958).

Keywords: Chronic obstructive pulmonary disease, Smoker, Behavioral intervention, Smoking cessation, Risk factors

\section{Background}

Chronic obstructive pulmonary disease (COPD) is a progressive systemic inflammatory disease that is usually an abnormal response to noxious particles and gases (more often, tobacco smoke) in susceptible individuals. Cigarette smoking is a worldwide risk factor for COPD [1,2], which accounts for $80-90 \%$ of COPD patients [3]. Løkke and colleagues found that smoking significantly increased the cumulative incidence of COPD in a 25 year follow up study [4]. The highest

\footnotetext{
* Correspondence: loupeian2004@yahoo.com.cn

${ }^{1}$ The Xuzhou Center for Disease Control and Prevention, 142 West Erhuan Road, Xuzhou City, Jiangsu Province, People's Republic of China 221006 Full list of author information is available at the end of the article
}

incidence for all stages of COPD was $35.5 \%$ that occurred in continuous smokers, while the incidence of never smokers was only 7.8\% [4]. Comparing cigarette smoking status in COPD patients, Zhou et al. found that the greater amount of smoking, the deeper inhalation into the airway and start smoking at earlier age had the greater risks of COPD [5]. Kanner et al. investigated mild stage of COPD patients continuously smoking, the speed of forced expiratory volume in 1 second $\left(\mathrm{FEV}_{1}\right)$ was declined when suffered from the lower airflow illness. Stopping smoking protected these people with mild COPD from this additional loss of lung function [6].

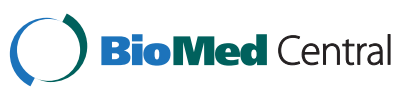

(c) 2013 Lou et al.; licensee BioMed Central Ltd. This is an Open Access article distributed under the terms of the Creative Commons Attribution License (http://creativecommons.org/licenses/by/2.0), which permits unrestricted use, distribution, and reproduction in any medium, provided the original work is properly cited. 
Quitting smoking is the most cost-effective method to prevent lung function deterioration for COPD patients. A longitudinal cohort study showed that continuous smokers had a much steep decline of lung function than those stopped smoking, while never smokers had the best lung function [7]. Lung Health Study confirmed that smoking cessation could reduce smoking-related decline in lung function $[8,9]$. When COPD patients with severely impaired lung function stopped smoking, their lung function might be not recovered, but the subsequent decline tend to be normal $[10,11]$. On the other hand, smoking cessation also improved airway hyperresponsiveness for COPD patients [12]. Smoking cessation at the early stage was able to benefit COPD prognosis $[7,8,11,13]$, which was more effective than stop smoking at the later stages
[14]. These data suggested the importance of COPD patients quit smoke as early as possible [5].

In China, over 40 million people suffered from COPD, and more than 1.28 million died from it every year [15]. About $80-90 \%$ of patients with COPD were smokers [16]. Although efficacious smoking cessation methods have been established for patients with COPD [17-19], no more stringent advice or pharmacological therapies have been applied for COPD patients to quit smoking compared with general smokers [20], and examined the influencing factors of community-based smoking cessation trial in current smokers with COPD in China especially.

In present study, we conducted a randomized controlled trial to assess the efficacy of a two-year course of behavioral interventions on helping patients with COPD to quit

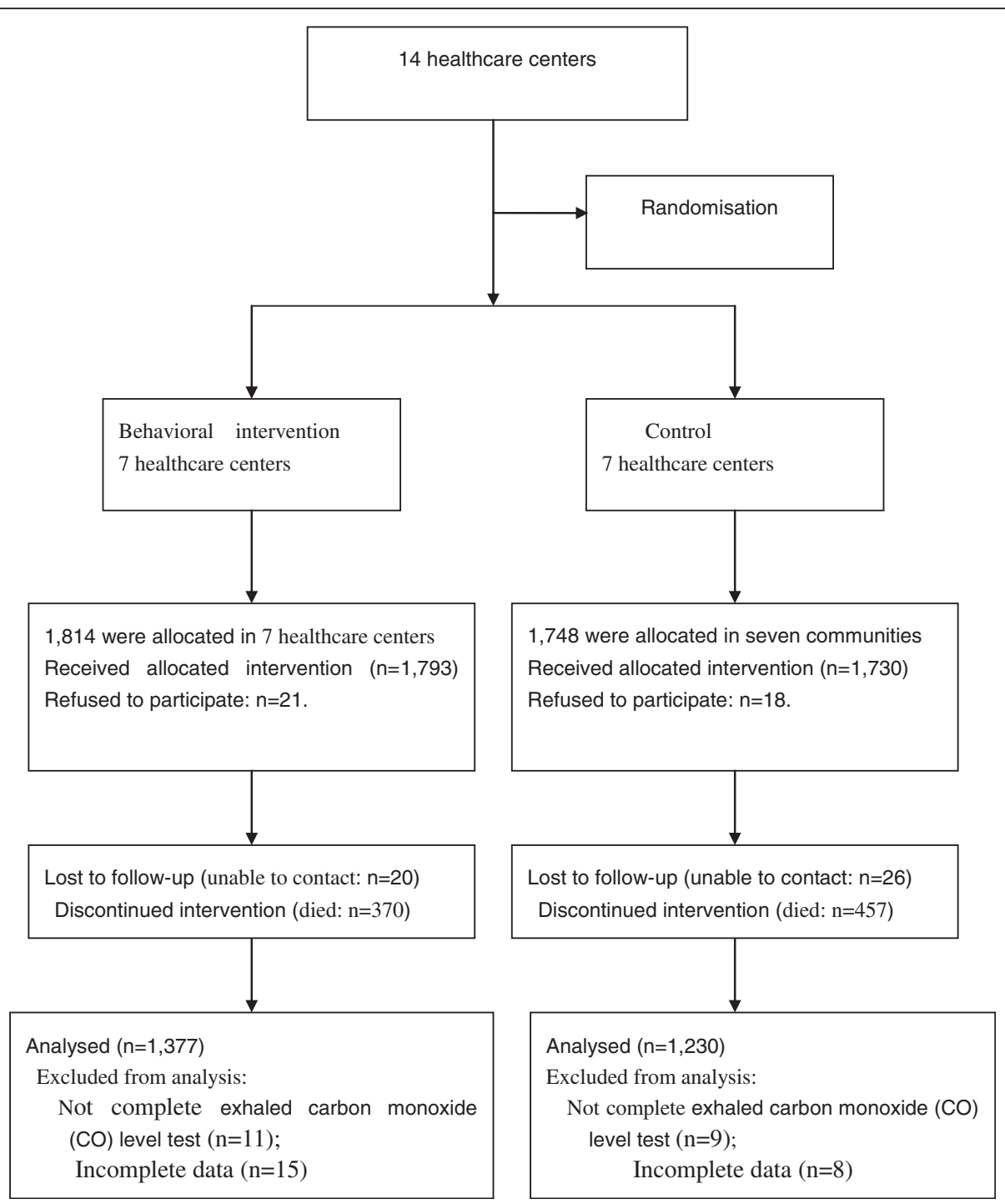

Figure 1 Consort figure of the trial profile. 
smoking, and explore potential factors potentially barring smoking cessation.

\section{Methods}

\section{Study design}

The study was a randomized controlled trial conducted form from January 2008 to May 2012, which involves three months patients' recruitment, two years' intervention, two years' monitoring. Recruitment of practices took place in 28 communities based on our previous epidemiological study [21]. Fourteen healthcare centers enrolled in the study; General healthcare centers in the intervention group received support to implement the behavioral intervention program, whereas the control healthcare centers delivered usual care. Randomization took place on healthcare center level. The healthcare centers were classified in two classes: with high or low task delegation from general practitioners to nurses. The healthcare centers in the classes were then randomly allocated to the groups (See: consort Figure 1).

A two-sided $\mathrm{P}$ value $<0.05$ was used. Based on a twosided Type 1 error $(\alpha)=0.05$, with an $80 \%$ power to detect a $25 \%$ relative reduction in quitting rates, allowing $20 \%$ loss during follow-up, we need that each group should contain a minimum of 7 healthcare centers $\mathrm{s}$ and at least 50 patients with COPD per group.

This study was approved by the Ethics Committee of the Xuzhou Center for Disease Control and Prevention and the Regional Ethical Vetting Board, Xuzhou, China. In addition, agreement was received from all of the relevant health centers. Informed consent was obtained from all participants.

\section{Subjects}

Patients were recruited by their family physicians from 14 healthcare units in rural area of Xuzhou city, China, from January to March 2008. Patients had to meet the following criteria at baseline: COPD diagnosed by the standards set forth by the Global Initiative for Chronic Obstructive Lung Disease (GOLD) [22]. Which means all participants underwent standard measurements of lung function (post-bronchodilator forced expiratory volume in $1 \mathrm{~s}\left(\mathrm{FEV}_{1}\right) /$ forced vital capacity $\left.(\mathrm{FVC})<70 \%\right)$ by the County People's Hospital. Reversibility of airways obstruction was measured according to standard America Thoracic Society guidelines (over 15\% and at least $400 \mathrm{ml}$ improvement in $\mathrm{FEV}_{1}$ after $400 \mu \mathrm{g}$ salbutamol via a spacer) [23]. The study population consisted of current smokers with all stage COPD. All patients were aged 35 years or older, had smoked 1 cigarette or more per day for the previous year, and had not stopped smoking for more than 3 months during that year. We excluded participants who had any serious or unstable medical disorders such as psychiatric that might affect lung function or they had a current diagnosis of major depression.

Participants were considered as loss to follow-up if they could not contact, died, move to another place, withdraw consent, refuse to proceed, invalid data, or unable to complete the study due to other reasons.

\section{Behavioral interventions}

During the screening phase, individuals selected a date to stop smoking (target day) and were told not to attempt to stop before this day. Patients were also told the aim of the study.136 general practitioners, working at 7 different healthcare centers of the intervention group, followed 6 hours training in behavioral interventions for quitting smoking. The training included: ingredients of tobacco, the potential harmful of smoking, smoking and COPD, harmful of exposure to tobacco smoke, smoking's impact on the economy, weigh the pros and cons of smoking and smoking cessation, why the COPD patients need quit smoke, benefits of quitting smoking, how to deal with smoking cravings, how to preventing relapse smoking, how to develop smoking cessation programs, how to help them quit smoking and the motivational interview.

The teams of general practitioners (including assistants and nurses) were established in the healthcare centers of intervention group. They were responsible for supervising and advising patients with COPD registering in their healthcare centers to quit smoke. The tasks of them included home visiting patients with COPD at least once a week, to obtain the current condition of quitting smoking, tell the patients how to do next, and record the time of quitting smoking. If a patient has quitted smoking, the general practitioners were to follow-up the patient once a week at the first month and afterwards once a month until the end the study. Meanwhile, they also were responsible for examining the exhaled carbon monoxide (CO) level for COPD patients. Every month, the participants were asked to meet together once to discuss relevant questions for quitting smoking and share the experience of quitting smoking. The professional group (including respiratory, rehabilitation, nutrition, sports and psychology specialists) routinely visited the COPD patients in healthcare centers every two months. The general practitioners in the healthcare centers reported the follow-up status of patient with COPD and smoking cessation conditions once a month. The professional group assessed smoking cessation conditions, developed the focus of the next follow-up period for each patient, and sent the focus to the teams of the general practitioners. The focus was how to improve patients' quitting smoking during next follow-up period. The professional group also provided other physiological supporting, including the benefits of smoking cessation and how to deal with obesity. This 
study was lasted four years. During the follow-up period, personnel support was offered with easily access for all participants. All participants were tested for exhaled carbon monoxide $(\mathrm{CO})$ level at the baseline and every six months in the follow-up period.

At the baseline, all patients were interviewed by the general practitioners and the professional group at healthcare centers. All participants were asked if they were willing to quit smoking. The participants who would like to quit smoking were given a booklet that included:

- how many harmful ingredients are in cigarettes;

- smoking and disease (included: COPD);

- Benefits of quitting smoking;

- how to deal with cravings for smoking;

- Ways to quit smoking.

For the patients in intervention group, we strongly encouraged them to stop smoking, and received brief smoking cessation advice after the baseline interview, which consist of 5-8 minutes' discussion with member of professional group about their smoking habits. Smoking cessation advice was focused on the risk of developing COPD, lung cancer, coronary artery disease, and the harmful effects to other family members. If the participants wanted to stop smoking, we provided them a plan to quit smoking. For example, we asked the participants to set date to stop smoking (target day). If the patients currently smoked twenty cigarettes per day, they could decrease two cigarettes per day or two days. If the patients did not want to stop smoking, we encouraged them to stop smoking within six months. They could decrease one cigarette per day or one week. It was suggested for all participants to postpone the time as long as possible when they want to smoke. Drinking water, talking with someone, or turning their attention on other things were recommended as effective ways to postpone smoking time. No pharmacological treatment for smoking addiction was provided in the current study.

\section{Smoking status}

An exhaled carbon monoxide (CO) measurement was taken at baseline and every six month in the follow-up period to confirm smoking status at healthcare centers. The primary efficacy measure was continuous abstinence from smoking for 2 years from the start of month 24 to the end of month30. We defined continuous abstinence as a participant report of zero cigarettes per day for at least 6 months and confirmed by exhaled carbon monoxide values of 10 parts per million

Secondary measures of efficacy were continuous abstinence during month 24-36 and 24-48. Continuous abstinence for months 24-48 was defined by participants being continuously abstinent during months 24-36, having a diary cigarette count of zero during weeks 37-48, and having exhaled carbon monoxide values of $10 \mathrm{ppm}$ or less at month 48 .

\section{Assessment of influencing factors}

All participates were asked to complete a questionnaires that included age, sex, current employment status, education level, marital status, physical activity, alcohol use, number of smoking family member, number of cigarettes smoked, motivation to stop smoking, smoking pack years (average daily numbers of cigarettes smoked divided by 20 and multiplied by the smoking years). Comorbidities including chronic bronchitis or emphysema, asthma, other lung disease, diabetes, treatment for blood pressure, stroke, coronary heart disease (angina or heart attack), or other heart disease and conditions were recorded on patient's baseline reports. Education was categorized into below high school, high school, or above high school levels. Alcohol drinking was defined as the consumption of at least $30 \mathrm{~g}$ of alcohol per week for one or more years. The height and weight were measured, and body mass index (BMI) was calculated (BMI = weight in kilograms divided by height in meters squared). BMI was categorized as underweight $\left(\leq 18.5 \mathrm{~kg} / \mathrm{m}^{2}\right)$, normal $(18.5$ to $\left.\leq 24.0 \mathrm{~kg} / \mathrm{m}^{2}\right)$ or overweight/obese $\left(\geq 24.0 \mathrm{~kg} / \mathrm{m}^{2}\right)$ [24]. Mental health (depression and anxiety) was evaluated by the Hospital Anxiety and Depression Scale (HADS) [25]. Dyspnea was measured using the Medical Research Council (MRC) dyspnea scale [26] and FagerstrÖm Test for Nicotine Dependence (FTND) [27].

\section{Usual care}

Participants in control group were treated by healthcare providers or general practitioners as usual manner. The

Table 1 Baseline characteristics within healthcare units

\begin{tabular}{lcc}
\hline & Intervention group & Control group \\
\hline No of units & 7 & 7 \\
Population & 301,785 & 298,467 \\
Annual per capita income (Yuan) & $21,345 \pm 464$ & $21,545 \pm 471$ \\
Per capita housing area $\left(\mathrm{m}^{2}\right)$ & $25.6 \pm 6.4$ & $25.6 \pm 6.5$ \\
medical staff & 2,162 & 2,147 \\
Medical staff constitute & & \\
Doctor & $654(38.1)$ & $648(37.0)$ \\
Nurse & $1,041(38.7)$ & $1,058(41.0)$ \\
Medical staff educational background & & 1,573 \\
Undergraduate or above & 1,576 & 479 \\
Junior college & 482 & 878 \\
Medical staff professional titles & & \\
Senior title & 559 & \\
Intermediate title & 881 & \\
\hline
\end{tabular}

Figures are numbers (percentages) unless stated otherwise. 
Table 2 The characteristics and smoking rates at the baseline

\begin{tabular}{|c|c|c|}
\hline Variables & $\begin{array}{l}\text { Intervention group } \\
(n=1,814)\end{array}$ & $\begin{array}{l}\text { Control group } \\
(n=1,748)\end{array}$ \\
\hline \multicolumn{3}{|l|}{ Sex } \\
\hline Men & $868(100)$ & $840(100)$ \\
\hline Women & $946(100)$ & $908(100)$ \\
\hline \multicolumn{3}{|l|}{ Age } \\
\hline $40 \sim$ & $292(100)$ & $279(100)$ \\
\hline $50 \sim$ & $370(100)$ & $358(100)$ \\
\hline $60 \sim$ & $507(100)$ & $490(100)$ \\
\hline $70 \sim$ & $478(100)$ & $463(100)$ \\
\hline $80 \sim$ & $167(100)$ & $158(100)$ \\
\hline \multicolumn{3}{|c|}{ Education level } \\
\hline High & $159(100)$ & $152(100)$ \\
\hline Middle & $327(100)$ & $323(100)$ \\
\hline Low & $1328(100)$ & $1273(100)$ \\
\hline \multicolumn{3}{|c|}{ Household income } \\
\hline High & $148(100)$ & $146(100)$ \\
\hline Middle & $1529(100)$ & $1466(100)$ \\
\hline Low & $137(100)$ & $136(100)$ \\
\hline
\end{tabular}

Alcohol user

$\begin{array}{lll}\text { Yes } & 659(100) & 628(100) \\ \text { No } & 1155(100) & 1120(100) \\ \text { Comorbidities } & & \\ \text { Yes } & 473(100) & 459(100) \\ \text { No } & 1341(100) & 1289(100)\end{array}$

Depression

Yes

No

Anxiety

Yes

$640(100)$

$622(100)$

$1126(100)$

$337(100)$

No

$343(100)$

$1471(100)$

$1411(100)$

Pack years$$
<30
$$

604 (100)

$30 \sim$

$648(100)$

40

$562(100)$

Nicotine addiction (FagerstrÖm score)

$\begin{array}{lll}0 \sim 3 & 526(100) & 502(100) \\ 4 \sim 6 & 648(100) & 654(100) \\ \geq 7 & 640(100) & 592(100)\end{array}$

MRC scales

$\begin{array}{lll}0 & 91(100) & 89(100) \\ 1 & 358(100) & 346(100) \\ 2 & 524(100) & 499(100) \\ 3 & 502(100) & 486(100) \\ 4 & 339(100) & 328(100)\end{array}$

Table 2 The characteristics and smoking rates at the baseline (Continued)

\begin{tabular}{lcl}
\hline Smoking history of family members & \\
Yes & $1128(100)$ & $1075(100)$ \\
No & $686(100)$ & $673(100)$ \\
Smoking history of the responsible doctor or nurse & \\
Yes & $798(100)$ & $778(100)$ \\
No & $1016(100)$ & $970(100)$ \\
\hline
\end{tabular}

MRC Medical Research Council.

content and number of usual care services were not standardized. Participants were follow-upped once every 2 months, and asked whether the symptoms aggravated, what medication they used, etc.

\section{Statistical analyses}

We did all analyses on the intention-to-treat population, which consisted of patients who took at least one month of our study. All participants who withdrew from the study were taken to be smokers thereafter.

SPSS for Windows version 11.5 (SPSS Inc.) was used for data analysis. Tests were considered as significant when $P<0.05$. Baseline demographic and smoking characteristics as well as mean scores of MRC, and mental health were compared to assess potential differences between intervention group and control. T-test was used to analyze the differences in mean scores between the groups. A chi-squared test was used to evaluate the statistical significance of smoking cessation rates between the two groups. We studied the effect of age, sex, education level, household income, alcohol user, depression, anxiety, smoking pack-years, Nicotine addiction, dyspnea, smoking history of family members and smoking history of the responsible doctor or nurse of patients with multivariate logistic regression. These variables were added to the basic model including intervention group assignment and centre. Candidate variables $(P<0.05)$ were entered into the multiple logistic regression models analysis to analyze risk factors affecting quit smoking. Odds ratios $(\mathrm{OR})$, confidence intervals $(\mathrm{CI})$ and $\mathrm{p}$ values were calculated.

\section{Results}

General characteristics of the participants at the baseline The two groups were drawn from a single district and were similar in annual averaged income, access to health services and main demography at baseline (Table 1).

Among 3562 smokers, 26.8\% did not complete the follow-up visit, i.e. 46 subjects had moved away from the region, 39 declined to participate in the follow-up visit for miscellaneous reasons, 20 did not complete exhaled carbon monoxide (CO) level test, 23 were incomplete data, and 827 died (intervention: 370 vs control: $457 ; \mathrm{X}^{2}=28.76$, 
Table 3 Abstinence rates during intervention and followup phases

\begin{tabular}{llll}
\hline Month & \multicolumn{2}{c}{ Continuous abstinence } & P \\
\cline { 2 - 3 } & $\begin{array}{l}\text { Intervention group } \\
(\mathbf{n}=\mathbf{1 3 7 7})\end{array}$ & $\begin{array}{l}\text { Control group } \\
(\mathbf{n}=\mathbf{1 2 3 0 )}\end{array}$ & \\
\hline 6 & $79(5.7 \%)$ & $3(0.2 \%)$ & $<0.001$ \\
12 & $198(14.4 \%)$ & $11(0.9 \%)$ & $<0.001$ \\
18 & $342(24.8 \%)$ & $24(2.0 \%)$ & $<0.001$ \\
24 & $508(36.9 \%)$ & $36(2.9 \%)$ & $<0.001$ \\
30 & $639(46.4 \%)$ & $42(3.4 \%)$ & $<0.001$ \\
36 & $630(45.8 \%)$ & $49(4.0 \%)$ & $<0.001$ \\
42 & $622(45.2 \%)$ & $57(4.6 \%)$ & $<0.001$ \\
48 & $610(44.3 \%)$ & $63(5.1 \%)$ & $<0.001$ \\
\hline
\end{tabular}

$\mathrm{P}<0.001)$. The total number of lost in behavioral intervention and control group were 437 and 518, respectively. Significant difference in lost rates was observed between behavioral intervention and control group $\left(x^{2}=13.94\right.$, $\mathrm{P}<0.001)$. There were no statistically significant differences in the smoking history, age and sex between those who attended the follow up and non-responders. Finally, 2607 subjects were analyzed in the study, 1377 in behavioral intervention group and 1230 in control group (Figure 1). In behavioral intervention group, the mean ages, median smoking years, median nicotine dependence scales and median MRC scales were $61.6 \pm 10.2$ years, $37.8 \pm 11.7$ pack-years, $5.1 \pm 2.1$ and $2.4 \pm 1.5$, respectively. In the control group, the mean age of $61.5 \pm$ 10.1 years, median smoking years of $37.6 \pm 11.5$ packyears, and median nicotine dependence scales of $5.0 \pm 1.9$. No statistically significant differences in these indicators were observed between the two groups. Other descriptive characteristics for behavioral intervention and control group were shown in Table 2. Which showed no statistically significant differences between the intervention and control groups (all Ps > 0.05).

\section{Quit smoking rates}

The rates of continuous abstinence from month 24 to the end of month 30 was higher in the intervention group than that in the control group ( $46.4 \%$ vs $3.4 \% \mathrm{p}<0.001$ ). 639 out of 1377 (46.4\% ) participants receiving behavioral intervention remained abstinent compared with 42 out of 1230 (3.4\%) receiving usual care. Rates of continuous abstinence were significantly higher with behavioral intervention than with usual care throughout the 24-month intervention phase and at the 48 month follow-up visit (Table 3). At the 48 month follow-up, more participants receiving behavioral intervention remained abstinent than those receiving usual care ( $44.3 \%$ vs $5.1 \%, \mathrm{p}<0.001)$. Behavioral intervention was significantly better than usual care at months $36-48$ during the follow-up phase $(\mathrm{p}<0.001)$.

The significant differences of continuous smoking abstinent rates were consistently observed for all subgroups (such as different ages, gender, education levels, household income, alcohol user and comorbidities etc.), i.e. higher smoking cessation rate in intervention group than that in control group (Table 4).

\section{Verified quit smoking}

The successful smoking cessation during the 4-year follow up was confirmed by a low exhaled CO level for 610 subjects. The mean exhaled $\mathrm{CO}$ in sustained quitters was significantly lower $($ mean $=3.7 \mathrm{ppm}, \mathrm{SD}=1.5)$ compared with continuous smokers $($ mean $=15.7 \mathrm{ppm}, \mathrm{SD}=5.1$, $p<0.001)$. Subjects who were continuous smokers also reported a reduced cigarettes smoked per day at the end of 4-year follow up (mean $=14.5, \mathrm{SD}=7.2$ ) compared to the baseline ( mean $=20.5, \mathrm{SD}=9.2$ ).

\section{Risk factors affecting smoking cessation}

Independent predictors of successful smoking cessation included women, older age, no-drinkers, comorbidities, lower HADS-anxiety (HADS-A), lower HADS -depression (HADS--D), less smoking pack years, lower FagerstrÖm score, and higher MRC score (Table 5). Patients were more likely to quit smoking if they had the family physicians/ nurses nonsmoking or no family member smoking (Table 5). In other words, the family physicians/nurses and family members smoking were two strong predictors of failure to quit smoking. Other confounders might also play a role. The multiple logistic regression analysis showed significant effects for alcohol drinkers, comorbidities, HADS-A, HADS-D, smoking pack years, FagerstrÖm score, MRC score, family members smoking, and the family physicians/nurses smoking as predictors of smoking cessation by adjusting age and gender (Table 5). The family members smoking was the strongest predictor of sustained smoking $(\mathrm{OR}=12.1)$.

\section{Discussion}

Our results show that the behavioral intervention group had the high rate of abstinence from smoking over 24 months in smokers with COPD compared with the control group. This advantage over usual care continued for 24 months after discontinuation of the behavioral intervention. It also shows that the family physicians/ nurses and family members smoking were two strong predictors for failure to quit smoking.

Overall, the population-attributable risk of COPD related to cigarette smoking was higher (about 45\%)[28,29]. Smoking cessation is an efficient way of slowing down COPD progression. The Lung Health Study (LHS) examined the effects of tobacco intervention on COPD 
Table 4 Observed frequencies of abstinence from month 31 to end of month 48

\begin{tabular}{|c|c|c|c|c|}
\hline Variables & Smoking cessation group $(n=1377)$ & Control group $(n=1230)$ & Difference $(95 \% \mathrm{Cl})$ & $P$ value \\
\hline \multicolumn{5}{|l|}{ Sex } \\
\hline Men (\%) & $265 / 659(40.2)$ & 28/601 (4.7) & $35.5(23.6-49.8)$ & $P<0.001$ \\
\hline Women & $345 / 718(48.0)$ & $35 / 628(5.6)$ & $42.4(27.8-58.6)$ & $P<0.001$ \\
\hline \multicolumn{5}{|l|}{ Age } \\
\hline $40 \sim$ & $87 / 221(39.4)$ & $5 / 197(2.5)$ & $36.9(29.5-45.6)$ & $P<0.001$ \\
\hline $50 \sim$ & $118 / 280(42.1)$ & $11 / 250(4.4)$ & $37.7(26.5-50.1)$ & $P<0.001$ \\
\hline $60 \sim$ & 171/385 (44.4) & $17 / 343(5.0)$ & $39.4(26.6-53.4)$ & $P<0.001$ \\
\hline $70 \sim$ & 167/362 (53.8) & $17 / 323(5.3)$ & $48.5(37.8-60.7)$ & $P<0.001$ \\
\hline $80 \sim$ & $67 / 129(51.9)$ & 13/117 (11.1) & $40.8(33.5-49.2)$ & $P<0.001$ \\
\hline \multicolumn{5}{|c|}{ Education level } \\
\hline High & $74 / 143(51.7)$ & $8 / 129(6.2)$ & $45.5(37.7-54.3)$ & $P<0.001$ \\
\hline Middle & 137/313 (43.8) & $14 / 280(5.1)$ & $38.7(25.4-53.2)$ & $P<0.001$ \\
\hline Low & 399/921 (43.3) & $41 / 821(5.0)$ & $38.3(20.6-57.3)$ & $P<0.001$ \\
\hline \multicolumn{5}{|c|}{ Household income } \\
\hline High & 48/112 (42.8) & $7 / 114(6.1)$ & $36.7(30.3-43.9)$ & $P<0.001$ \\
\hline Middle & $524 / 1173(44.7)$ & $53 / 1051(5.0)$ & 39.7 (20.5-59.8) & $P<0.001$ \\
\hline Low & $38 / 92(41.2)$ & 3/65 (4.6) & $36.6(31.3-42.4)$ & $P<0.001$ \\
\hline \multicolumn{5}{|c|}{ Alcohol user } \\
\hline Yes & 201/498 (40.4) & 17/434 (3.9) & $36.5(25.6-49.4)$ & $P<0.001$ \\
\hline No & 409/879 (46.5) & 46/796 (5.8) & $40.7(26.4-56.1)$ & $P<0.001$ \\
\hline Comorbidit & & & & $P<0.001$ \\
\hline Yes & 68/136 (50.0) & 15/121 (12.4) & $37.6(25.3-55.4)$ & $P<0.001$ \\
\hline No & $542 / 1241(43.4)$ & 48/1109 (3.9) & 39.5 (20.7-58.6) & $P<0.001$ \\
\hline \multicolumn{5}{|l|}{ Depression } \\
\hline Yes & $95 / 513 /(18.5)$ & $13 / 518(2.5)$ & $16.0(12.7-20.5)$ & $P<0.001$ \\
\hline No & 515/864 (59.6) & $50 / 712(7.0)$ & $52.6(41.9-63.5)$ & $P<0.001$ \\
\hline Anxiety & & & & $P<0.001$ \\
\hline Yes & $81 / 258(31.4)$ & $9 / 230(4.0)$ & $27.4(20.1-35.7)$ & $P<0.001$ \\
\hline No & $529 / 1119(47.3)$ & $54 / 1000(5.4)$ & $42.1(33.3-51.1)$ & $P<0.001$ \\
\hline \multicolumn{5}{|l|}{ Pack years } \\
\hline$<30$ & 266/564 (47.2) & $32 / 504(6.3)$ & $40.9(32.4-50.4)$ & $P<0.001$ \\
\hline $30 \sim$ & 200/454 (44.1) & 18/406 (4.4) & $39.7(31.8-48.2)$ & $P<0.001$ \\
\hline $40 \sim$ & 144/359 (40.1) & $13 / 320(4.1)$ & $36.0(29.7-43.3)$ & $P<0.001$ \\
\hline \multicolumn{5}{|c|}{ Nicotine addiction (FagerstrÖm score) } \\
\hline $0 \sim 3$ & 243/432 (56.3) & $25 / 386(6.5)$ & $49.8(35.6-64.6)$ & $P<0.001$ \\
\hline $4 \sim 6$ & 233/486 (47.9) & 23/434 (5.3) & $42.6(29.1-56.7)$ & $P<0.001$ \\
\hline$\geq 7$ & 134/459 (29.2) & $15 / 320(4.7)$ & $24.5(13.4-36.6)$ & $P<0.001$ \\
\hline \multicolumn{5}{|l|}{ MRC scales } \\
\hline 0 & $21 / 70(30.0)$ & $2 / 71(2.8)$ & $27.2(22.6-32.3)$ & $P<0.001$ \\
\hline 1 & 107/272 (39.3) & $7 / 243(2.9)$ & $36.4(27.5-46.3)$ & $P<0.001$ \\
\hline 2 & 175 /398 (44.0) & 17/356 (4.8) & $39.2(27.7-51.7)$ & $P<0.001$ \\
\hline 3 & 178/380 (46.8) & 20/339 (5.9) & $40.9(28.1-54.4)$ & $P<0.001$ \\
\hline 4 & $129 / 257(50.2)$ & 15/221 (6.8) & $43.4(31.1-56.7)$ & $P<0.001$ \\
\hline
\end{tabular}


Table 4 Observed frequencies of abstinence from month 31 to end of month 48 (Continued)

\begin{tabular}{|c|c|c|c|c|}
\hline \multicolumn{5}{|c|}{ Smoking history of family members } \\
\hline Yes & 247/816 (30.3) & $28 / 729(3.8)$ & $26.5(13.2-40.1)$ & $P<0.001$ \\
\hline No & $363 / 561(64.7)$ & $37 / 501(7.4)$ & $57.3(38.9-76.2)$ & $P<0.001$ \\
\hline \multicolumn{5}{|c|}{ Smoking history of the responsible doctor or nurse } \\
\hline Yes & $214 / 589(36.3)$ & $22 / 526(4.2)$ & $32.1(21.7-43.9)$ & $P<0.001$ \\
\hline No & $396 / 788(50.3)$ & $41 / 704(5.8)$ & $44.5(32.1-57.6)$ & $P<0.001$ \\
\hline
\end{tabular}

progression among current smokers [8]. The smokers with mild to moderate COPD were followed up at 4-month intervals to check on smoking status and the compliance with smoking cessation determined by self-report and verified by measuring expired carbon monoxide and salivary cotinine levels. Over the 4 years of follow-up, $22 \%$ of patients with COPD were continuous abstinence smokers in two groups receiving special tobacco treatment. In contrast, only $5 \%$ of the patients in usual care group became continuous abstinence smokers. Smoking habits by original Lung Health Study treatment groups tended to converge, but $93 \%$ of participants who were abstinent throughout the Lung Health Study were still abstinent at 11 years [30]. Our behavioral intervention showed a consistent and significantly higher continuous smoking abstinence rate (44.3\%) in patients with COPD compared with control group (5.7\%) after four years. We also found that $22.6 \%$ of smokers reduced the amount of cigarettes smoked. These data highlighted the feasibility and efficacy to conduct community-based smoking cessation in patients with COPD. The long term follow-up studies are warrant to evaluate the longitudinal effects of smoking cessation.

Our study also identified several important factors which potentially impact smoking cessation, including women, older, non-drinkers, comorbidities and dyspnea. Patients with depression, anxiety, higher smoking pack years and nicotine addiction were difficult to quit smoking. These results provided additional information and potential methods to improve the management of COPD patients. For example, a previous study found that female smokers with COPD might experience a faster decline in lung function than male smokers [31]. Another study indicated that female smokers had larger gains in lung function when stopped smoking compared with male quitters [32]. These data strongly suggested that smoking cessation was particularly important for women because they had increased susceptibility to COPD progression if continued smoking, but may obtain more benefits if quitting smoking compared with male smokers. These results could be used as strong biological evidence and tools in conducting community-based intervention to convince women quit smoking. It was also consistent with our observational study that women with COPD were relatively easy to quit smoking.
Table 5 Multiple logistic regression analyses for factors associated with failure smoking cessation

\begin{tabular}{lccc}
\hline Variable & OR & $\mathbf{9 5 \% ~ C l}$ & P values \\
\hline Gender & & & \\
Female & 1.00 & & $<0.001$
\end{tabular}

Male $\quad 1.50 \quad 1.28-1.77$

Comorbidities

No $\quad 1.00$

Yes 1. 19

$1.08-1.38$

Alcohol drinking

No $\quad 1.00$

Yes $\quad 0.61$

$0.51-0.72$

Depression

No $\quad 1.00$

0.003

$\begin{array}{lll}\text { Yes } & 1.26 & 1.09-1.40\end{array}$

Anxiety

No $\quad 1.00$

0.000

$\begin{array}{lll}\text { Yes } & 1.25 & 1.07-1.43\end{array}$

Pack years

$<30 \quad 1.00$

$30 \sim$

40 $\quad 1.55$

$1.01-1.24$

0.009

Nicotine addiction (FagerstrÖm score)

$0 \sim 3.00$

$4 \sim 6 \quad 1.25$

$1.25 \quad 1.09-1.49$

0.002

$\begin{array}{llll}\geq 7 & 1.62 & 1.29-2.15 & 0.000\end{array}$

MRC scales

$4 \quad 1.00$

$\begin{array}{llll}3 & 1.37 & 1.12-1.66 & 0.001\end{array}$

$\begin{array}{llll}2 & 1.52 & 1.28-1.81 & 0.000\end{array}$

$\begin{array}{llll}1 & 1.65 & 1.35-2.01 & 0.000\end{array}$

$\begin{array}{llll}0 & 1.72 & 1.37-2.21 & 0.000\end{array}$

Family member smoking

$\begin{array}{lll}\text { No } & 1.00 & 0.000\end{array}$

$\begin{array}{lll}\text { Yes } & 12.1 & 18.7-35.2\end{array}$

Family doctor smoking

No $\quad 1.00$

0.000

Yes $\quad 4.7$

$2.26-10.4$

MRC Medical Research Council. 
For the first time, we found two important factors (family members smoking and family physicians smoking) were significantly associated with smoking cessation in China. Luker conducted a systematic review to assess the effectiveness of family-focused smoking cessation interventions for patients with COPD [33]. However, no conclusion was obtained about the effectiveness of a family-focused intervention, including factors of marital status, smoking status of household members and support for smoking cessation. The negative impact of smoked doctors or nurses on smoking cessation of COPD patients displayed a great challenge we faced on community-based intervention. The doctors or nurses usually provided a positive attitude and health knowledge to persuade COPD patients to quit smoking, which played a critical role in improving the efficacy of smoking cessation intervention. The message that "quitting smoking benefits your health or disease progression" may not be convincible if provided by doctors or nurses who are smokers. On the other hand, our data also suggested that there is a lot of space to improve the smoking cessation if we can firstly persuade the doctor or nurse to quit smoking.

The strengths of current study included a communitybased intervention design, large sample size, randomly selected intervention and control groups, and low rate of loss of follow-up. The accurate smoking cessation data obtained by both questionnaires and exhaled $\mathrm{CO}$ measurement also made the current results more reliable. One limitation was a moderate duration (four years) that could not evaluate the long-term efficacy of smoking cessation. No detailed data on comparison lung functions and other clinical outcomes of COPD patients before and after smoking cessation is also limited, which may potentially reduce the efficacy of quitting smoking. Previous studies have demonstrated that smoking cessation was associated with a slower decline in lung function and reduced risk of hospitalization and total mortality in another study [8]. Knowing smokers' lung function being declining might help motivate patients to quit smoking $[18,34,35]$. This data strongly encouraged us to adopt lung function detection in the community-based intervention to improve the efficacy of smoking cessation.

\section{Conclusions}

In summary, our community-based study revealed twoyear behavior intervention significantly decreased smoking rate in currently smoked patients with COPD. Several important factors have been identified to positively or negatively impact smoking cessation, especially the smoking behaviors of other family members and the responsible doctors or nurses that were first associated with smoking cessation. Long-term follow-up for smoked patients with COPD and validating their lung functions may further improve the effect of community-based intervention, and benefit the prognosis of COPD patients.
Competing interests

The authors declare that they have no competing interests.

\section{Authors' contributions}

$\mathrm{LZ}$ and $\mathrm{PL}$ participated in writing the title and abstract, contributing to the writing of the manuscript drafts and reviewing the full text. YN conceptualized the study, participated in its design, title and abstract screening, full text screening, data extraction and analysis, and drafting of the manuscript. PC and PZ performed literature searches, participated in title and abstract screening, full text review, and contributed to the manuscript drafts. JY and NZ conceptualized the study; participated in its design, title and abstract screening, full text screening; and contributed to the manuscript drafts. NC and LZ contributed to the conception of the study, participated in the study design, and contributed to the manuscript drafts. HW and JZ were the lead authors of the original review, contributed to the conception of the study, participated in the study design, and contributed to the manuscript drafts. All authors have read and approved the final manuscript.

\section{Acknowledgements}

This research was funded by the Science and Technology Projects of Xuzhou City in 2007 (XM07C037). The researchers were independent from funding organizations. Funders of this study had no influence on the study design, data collection, analysis, interpretation of data, writing of the report, or the decision to submit the article for publication.

\section{Author details}

${ }^{1}$ The Xuzhou Center for Disease Control and Prevention, 142 West Erhuan Road, Xuzhou City, Jiangsu Province, People's Republic of China 221006.

${ }^{2}$ Department of Respiratory Medicine, Hospital of Xuzhou medical college, 99 West Huaiai Road, Xuzhou City, Jiangsu Province, People's Republic of China 221006.

Received: 20 March 2013 Accepted: 18 June 2013

Published: 27 June 2013

\section{References}

1. Celli BR, MacNee W: Standards for the diagnosis and treatment of patients with COPD: a summary of the ATS/ERS position paper. Eur Respir J 2004, 23:932-946.

2. Hurd S, Pauwels R: Global Initiative for Chronic Obstructive Lung Diseases (GOLD). Pulm Pharmacol Ther 2002, 15:353-355.

3. Collishaw NE: The Tobacco Epidemic: A Global Public Health Emergency Tobacco. Geneva: World Health Organization; 1996.

4. Lokke A, Lange P, Scharling H, Fabricius P, Vestbo J: Developing COPD: a 25 year follow up study of the general population. Thorax 2006, 61:935-939.

5. Zhou Y, Wang C, Yao W, Chen P, Kang J, Huang S, et al: COPD in Chinese nonsmokers. Eur Respir J 2009, 33:509-518.

6. Kanner RE, Anthonisen NR, Connett JE: Lower respiratory illnesses promote FEV(1) decline in current smokers but not ex-smokers with mild chronic obstructive pulmonary disease: results from the lung health study. Am J Respir Crit Care Med 2001, 164:358-364.

7. Xu X, Dockery DW, Ware JH, Speizer FE, Ferris BG Jr: Effects of cigarette smoking on rate of loss of pulmonary function in adults: a longitudinal assessment. Am Rev Respir Dis 1992, 146:1345-1348.

8. Anthonisen NR, Connett JE, Kiley JP, Altose MD, Bailey WC, Buist AS, et al: Effects of smoking intervention and the use of an inhaled anticholinergic bronchodilator on the rate of decline of FEV1. The Lung Health Study. JAMA 1994, 272:1497-1505.

9. Simmons MS, Connett JE, Nides MA, Lindgren PG, Kleerup EC, Murray RP, et al: Smoking reduction and the rate of decline in $\mathrm{FEV}(1)$ : results from the Lung Health Study. Eur Respir J 2005, 25:1011-1017.

10. Fletcher $C$, Peto $R$ : The natural history of chronic airflow obstruction. Br Med J 1977, 1:1645-1648.

11. Godtfredsen NS, Lam TH, Hansel TT, Leon ME, Gray N, Dresler C, et al: COPD-related morbidity and mortality after smoking cessation: status of the evidence. Eur Respir J 2008, 32:844-853.

12. Willemse BW, ten Hacken NH, Rutgers B, Lesman-Leegte IG, Timens W, Postma DS: Smoking cessation improves both direct and indirect airway hyperresponsiveness in COPD. Eur Respir J 2004, 24:391-396. 
13. Kanner RE, Connett JE, Williams DE, Buist AS: Effects of randomized assignment to a smoking cessation intervention and changes in smoking habits on respiratory symptoms in smokers with early chronic obstructive pulmonary disease: the Lung Health Study. Am J Med 1999, 106:410-416.

14. Tashkin D, Kanner R, Bailey W, Buist S, Anderson P, Nides M, Gonzales D, Dozier G, Patel MK, Jamerson B: Smoking cessation in patients with chronic obstructive pulmonary disease: a double-blind, placebo-controlled, randomised trial. Lancet 2001, 357:1571-1575.

15. Bureau of disease prevention and control of ministry of Health of the people's republic of China: Chinese center for disease prevention and control. Report on chronic disease in China 2006, 5. http://www.moh.gov. $\mathrm{cn} / \mathrm{wsb} / \mathrm{pzcjd} / 200804 / 20809 . \mathrm{shtml}$

16. Chinese Society of Respiratory Disease copdg: Diagnosis and treaAtment guidelines of chronic obstructive pulmonary disease (revised edition in 2007). Chin J Intern Med 2007, 46:254-261.

17. Kotz AD, Huibers MJH, West RJ, Wesseling G, van Schayck OCP: What mediates the effect of confrontational counselling on smoking cessation in smokers with COPD? Patient Educ Couns 2009, 76:16-24.

18. Pieterse ME, Seydel ER, DeVries H, Mudde AN, Kok GJ: Effectiveness of a Minimal Contact Smoking Cessation Program for Dutch General Practitioners: A Randomized Controlled Trial. Prev Med 2001, 32:182-190.

19. Hilberink SR, Jacobs JE, Bottema BJAM, de Vries H, Grol RPTM: Smoking cessation in patients with COPD in daily general practice (SMOCC): Six months' results. Prev Med 2005, 41:822-827.

20. Vozoris NT, Stanbrook MB: Smoking prevalence, behaviours, and cessation among individuals with COPD or asthma. Respir Med 2011, 105:477-484.

21. Lou P, Zhu Y, Chen P, Zhang P, Yu J, Zhang N, Chen N, Zhang L, Wu H, Zhao J: Vulnerability, beliefs, treatments and economic burden of chronic obstructive pulmonary disease in rural areas in China: a cross-sectional study. BMC Publ Health 2012, 12:287.

22. Global initiative for chronic obstructive pulmonary disease: Global strategy for the diagnosis, management, and prevention of chronic obstructive pulmonary disease. http://www.goldcopd.org/uploads/users/files/ GOLD_Report_2011_Jan21.pdf.

23. American Thoracic Society: Standardization of Spirometry, 1994 Update. Am J Respir Crit Care Med 1995, 152:1107-1136.

24. Haseli-Mashhadi N, Dadd T, Pan A, Yu Z, Lin X, Franco OH: Sleep quality in middle-aged and elderly Chinese: distribution, associated factors and associations with cardio-metabolic risk factors. BMC Publ Health 2009, 9:130.

25. Zigmond AS, Snaith RP: The hospital anxiety and depression scale. Acta Psychiatr Scand 1983, 67:361-370.

26. Bestall JC, Paul EA, Garrod R, Garnham R, Jones PW, Wedzicha JA: Usefulness of the Medical Research Council (MRC) dyspnoea scale as a measure of disability in patients with chronic obstructive pulmonary disease. Thorax 1999, 54:581-586.

27. Heatherton TF, Kozlowski LT, Frecker RC, Fagerstrom KO: The Fagerstrom Test for Nicotine Dependence: a revision of the Fagerstrom Tolerance Questionnaire. Br J Addict 1991, 86:1119-1127.

28. Lundback $B$, Lindberg $A$, Lindstrom $M$, Ronmark $E$, Jonsson $A C$, Jonsson $E$, et al: Not 15 but $50 \%$ of smokers develop COPD?-Report from the Obstructive Lung Disease in Northern Sweden Studies. Respir Med 2003, 97:115-122.

29. Mannino DM, Buist AS, Petty TL, Enright PL, Redd SC: Lung function and mortality in the United States: data from the First National Health and Nutrition Examination Survey follow up study. Thorax 2003, 58:388-393.

30. Anthonisen NR, Connett JE, Murray RP: Smoking and lung function of Lung Health Study participants after 11 years. Am J Respir Crit Care Med 2002, 166:675-679.

31. Murray RP, Anthonisen NR, Connett JE, Wise RA, Lindgren PG, Greene PG, et al: Effects of multiple attempts to quit smoking and relapses to smoking on pulmonary function. Lung Health Study Research Group. J Clin Epidemiol 1998, 51:1317-1326.

32. Connett JE, Murray RP, Buist AS, Wise RA, Bailey WC, Lindgren PG, et al: Changes in smoking status affect women more than men: results of the Lung Health Study. Am J Epidemiol 2003, 157:973-999.

33. Luker KA, Chalmers Kl, Caress AL, Salmon MP: Smoking cessation interventions in chronic obstructive pulmonary disease and the role of the family: a systematic literature review. J Adv Nurs 2007, 59:559-568.
34. Kotz D, Wesseling G, Huibers MJ, van Schayck OC: Efficacy of confronting smokers with airflow limitation for smoking cessation. Eur Respir J 2009, 33:754-762.

35. Stratelis G, Molstad S, Jakobsson P, Zetterstrom O: The impact of repeated spirometry and smoking cessation advice on smokers with mild COPD. Scand J Prim Health Care 2006, 24:133-139.

doi:10.1186/1471-2296-14-91

Cite this article as: Lou et al:: Supporting smoking cessation in chronic obstructive pulmonary disease with behavioral intervention: a randomized controlled trial. BMC Family Practice 2013 14:91.

\section{Submit your next manuscript to BioMed Central and take full advantage of:}

- Convenient online submission

- Thorough peer review

- No space constraints or color figure charges

- Immediate publication on acceptance

- Inclusion in PubMed, CAS, Scopus and Google Scholar

- Research which is freely available for redistribution

Submit your manuscript at www.biomedcentral.com/submit
C) BioMed Central 